Article

\title{
Exploring the History of Chloroplast Capture in Arabis Using Whole Chloroplast Genome Sequencing
}

\author{
Akira Kawabe * (D), Hiroaki Nukii and Hazuka Y. Furihata \\ Faculty of Life Sciences, Kyoto Sangyo University, Kyoto, Kyoto 603-8555, Japan; \\ g1447799@cc.kyoto-su.ac.jp (H.N.); hazuka.furi@cc.kyoto-su.ac.jp (H.Y.F.) \\ * Correspondence: akiraka@cc.kyoto-su.ac.jp; Tel.: +81-75-705-3126
}

Received: 26 January 2018; Accepted: 16 February 2018; Published: 18 February 2018

\begin{abstract}
Chloroplast capture occurs when the chloroplast of one plant species is introgressed into another plant species. The phylogenies of nuclear and chloroplast markers from East Asian Arabis species are incongruent, which indicates hybrid origin and shows chloroplast capture. In the present study, the complete chloroplast genomes of A. hirsuta, A. nipponica, and A. flagellosa were sequenced in order to analyze their divergence and their relationships. The chloroplast genomes of $A$. nipponica and A. flagellosa were similar, which indicates chloroplast replacement. If hybridization causing chloroplast capture occurred once, divergence between recipient species would be lower than between donor species. However, the chloroplast genomes of species with possible hybrid origins, A. nipponica and A. stelleri, differ at similar levels to possible maternal donor species $A$. flagellosa, which suggests that multiple hybridization events have occurred in their respective histories. The mitochondrial genomes exhibited similar patterns, while A. nipponica and A. flagellosa were more similar to each other than to A. hirsuta. This suggests that the two organellar genomes were co-transferred during the hybridization history of the East Asian Arabis species.
\end{abstract}

Keywords: Arabis; chloroplast capture; Brassicaceae

\section{Introduction}

The genus Arabis includes about 70 species that are distributed throughout the northern hemisphere. The genus previously included many more species, but a large number of these were reclassified into other genera, including Arabidopsis, Turritis, and Boechera, Crucihimalaya, Scapiarabis, and Sinoarabis [1-6]. Because of their highly variable morphology and life histories, Arabis species have been used for ecological and evolutionary studies of morphologic and phenotypic traits [7-11]. The whole genome of Arabis alpina has been sequenced, providing genomic information for evolutionary analyses $[12,13]$.

Molecular phylogenetic studies of Arabis species have been conducted to determine species classification and also correlation to morphological evolution of Arabis species [10,14,15]. Despite having similar morphologies, A. hirsuta from Europe, North America, and East Asia have been placed in different phylogenetic positions and are now considered distinct species. For example, East Asian A. hirsuta, which was previously classified as A. hirsuta var. nipponica, is now designated as A. nipponica [16]. Meanwhile, nuclear ITS sequences indicated that $A$. nipponica, A. stelleri, and A. takeshimana were closely related to European $A$. hirsuta. However, chloroplast trnLF sequences indicated that the species were closely related to East Asian Arabis species [14,16]. Such incongruent nuclear and organellar phylogenies have been reported from in other plant species and this is generally known as "chloroplast capture" $[17,18]$, which is a process that involves hybridization and many successive backcrosses [17]. When chloroplast capture happens, the chloroplast genome of a species is replaced by another species' chloroplast genome. A. nipponica may have originated 
from the hybridization of A. hirsuta or A. sagittata and East Asian Arabis species (similar to A. serrata, A. paniculata, and $A$. flagellosa), which act as paternal and maternal parents, respectively [14,16]. However, the evolutionary history and hybridization processes of $A$. nipponica and other East Asian Arabis species still need to be clarified. Because these conclusions for incongruence between nuclear and chloroplast phylogenies came from analyzing a small number of short sequences, hybridized species, the divergence level, and the classification of species are somewhat ambiguous. In the present study, the whole chloroplast genomes of three Arabis species were sequenced in order to analyze their divergence and evolutionary history. The whole chloroplast genome sequences also provide a basis for future marker development.

\section{Results}

\subsection{Chloroplast Genome Structure of Arabis Species}

The structures of the whole chloroplast genomes are summarized in Table 1, which also includes previously reported Arabis chloroplast genomes and the chloroplast genome of the closely related species Draba nemorosa. The chloroplast genome structure identified in the present study is shown as a circular map (see Figure 1). The complete chloroplast genomes of the Arabis species had total lengths of $152,866-153,758$ base pairs, which included 82,338 to 82,811 base pair long single copy (LSC) regions and 17,938 to 18,156 base pair short single copy (SSC) regions, which were separated by a pair of 26,421 to 26,933 base pair inverted repeat (IR) regions. The structure and length are conserved, and are similar to other Brassicaceae species' chloroplast genome sequences [19-22]. The complete genomes contain 86 protein-coding genes, 37 tRNA genes, and eight rRNA genes. Of these, seven protein-coding genes, seven tRNA genes, and four rRNA genes were located in the IR regions, and were therefore duplicated. The rps16 gene became a pseudogene in A. flagellosa, A. hirsuta, and A. nipponica strain Midori, which was previously reported as a related species [23]. In addition, the rps16 sequences of D. nemorosa, A. stelleri, A. flagellosa, A. hirsuta, and A. nipponica shared a 10 base pair deletion in the first exon, while A. stelleri, A. flagellosa, A. hirsuta, and A. nipponica shared a 1 base pair deletion in the second exon and $D$. nemorosa lacked the second exon entirely. The rps16 sequence of $A$. alpina also lacked part of the second exon and had mutations in the start and stop codons. Therefore, different patterns of rps16 pseudogenization were observed in A. alpina and the other Arabis species, as was previously suggested [23]. The A. alpina lineage had acquired independent dysfunctional mutation(s). The patterns observed for the European A. hirsuta revealed that the pseudogenization of rps16 in the other Arabis species might not have occurred independently but, instead, occurred before the divergence of $D$. nemorosa and other Arabis species after splitting from A. alpina.

Table 1. Summary of chloroplast genome structure in Arabis species.

\begin{tabular}{|c|c|c|c|c|c|c|c|c|c|c|c|}
\hline \multirow{2}{*}{ Species } & \multirow{2}{*}{ Strain } & \multicolumn{4}{|c|}{ Nucleotide Length (bp) } & \multicolumn{4}{|c|}{ GC Contents (\%) } & \multirow{2}{*}{ NCBI \# } & \multirow{2}{*}{ Reference } \\
\hline & & Entire & LSC & SSC & IR & Entire & LSC & SSC & IR & & \\
\hline Draba nemorosa & JO21 & 153289 & 82457 & 18126 & 26353 & 36.47 & 34.27 & 29.3 & 42.39 & $\begin{array}{c}\text { AP009373 } \\
(\mathrm{NC} 009272)\end{array}$ & \\
\hline Arabis alpina & & 152866 & 82338 & 17938 & 26933 & 36.45 & 34.21 & 29.31 & 42.39 & $\begin{array}{c}\text { HF934132 } \\
\text { (NC023367) }\end{array}$ & [25] \\
\hline Arabis hirsuta & Brno & 153758 & 82710 & 18156 & 26446 & 36.4 & 34.15 & 29.16 & 42.41 & LC361350 & this study \\
\hline Arabis flagellosa & Kifune & 153673 & 82775 & 18052 & 26423 & 36.4 & 34.13 & 29.22 & 42.41 & LC361351 & this study \\
\hline Arabis stelleri & & 153683 & 82807 & 18030 & 26423 & 36.39 & 34.11 & 29.22 & 42.42 & KY126841 & {$[23]$} \\
\hline Arabis nipponica & $\mathrm{JO} 23$ & 153689 & 82811 & 18036 & 26421 & 36.4 & 34.1 & 29.31 & 42.42 & $\begin{array}{c}\text { AP009369 } \\
\text { (NC009268) }\end{array}$ & \\
\hline Arabis nipponica & Midori & 153668 & 82772 & 18052 & 26422 & 36.39 & 34.1 & 29.24 & 42.42 & LC361349 & this study \\
\hline
\end{tabular}



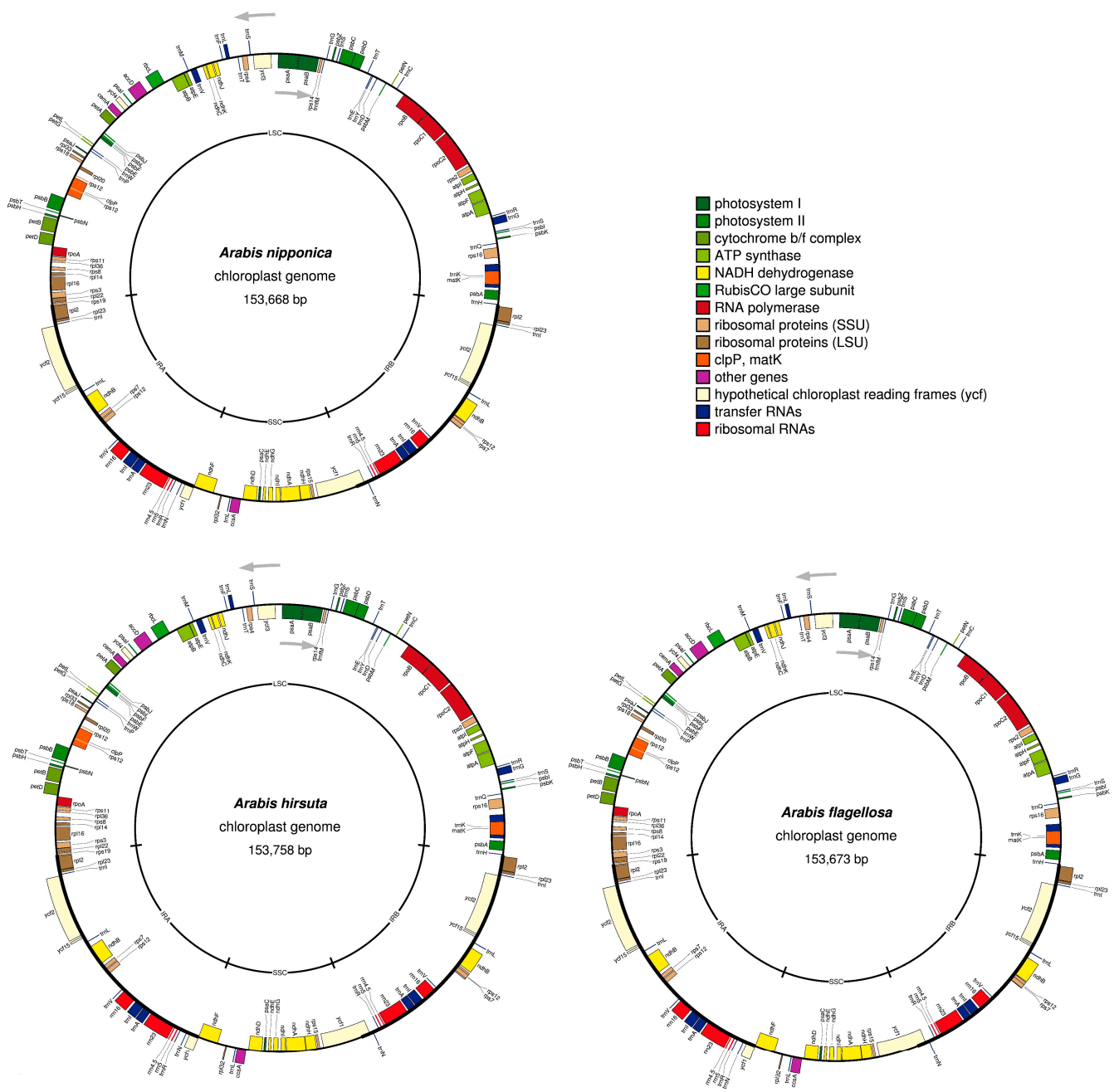

Figure 1. Chloroplast genome structure of Arabis species. Genes shown outside the map circles are transcribed clockwise, while those drawn inside are transcribed counterclockwise. Genes from different functional groups are color-coded according to the key at the top right. The positions of long single copy (LSC), short single copy (SSC), and two inverted repeat (IR: IRA and IRB) regions are shown in the inner circles.

\subsection{Chloroplast Genome Divergence}

Phylogenetic trees were generated by using whole chloroplast genome sequences and concatenated coding sequence (CDS) regions (see Figure 2). The inclusion of other Brassicaceae members revealed that $D$. nemorosa should be placed within Arabis, as previously reported [24]. In both trees, the two A. nipponica strains were grouped with A. flagellosa and A. stelleri. Although several nodes were supported by high bootstrap probabilities, the nearly identical sequences of the four East Asian Arabis species made them indistinguishable.

The divergence among the Arabis chloroplast genomes was shown using a VISTA plot (see Figure 3) and this was summarized in Table 2. The genome sequences of the two Japanese A. nipponica strains differed by only 55 nucleotide substitutions ( $0.036 \%$ per site), while those of $A$. hirsuta and $A$. nipponica differed by about 3500 sites (2.4\% per site). The chloroplast genomes of A. nipponica and the other two East Asian Arabis species were also very similar ( 100 nucleotide differences, $<0.1 \%$ per site). Additionally, the 35 CDS regions, 29 tRNA genes, and four rRNA genes of the four East Asian Arabis species were identical, with three, 27, and four, respectively, also found to be identical in A. hirsuta. The levels of divergence between the East Asian Arabis species were similar to previously 
reported levels of variation within the local A. alpina population, in which 130 SNPs were identified among 24 individuals (Waterson's $\theta=0.02 \%$ ) [25]. If the hybridization event had facilitated chloroplast capture, the divergence between the $A$. stelleri and $A$. nipponica chloroplast genomes should have been less than their divergence from $A$. flagellosa. However, the divergence between the potential hybrid-origin species (A. stelleri and A. nipponica: 0.068 to 0.085 ) was similar to their divergence from A. flagellosa (0.056 to 0.086$)$. Although the level of divergence was too low to make reliable comparisons, it is possible that $A$. stelleri and A. nipponica originated from independent hybridization events or the introgression process may still be ongoing.

A) Entire genome

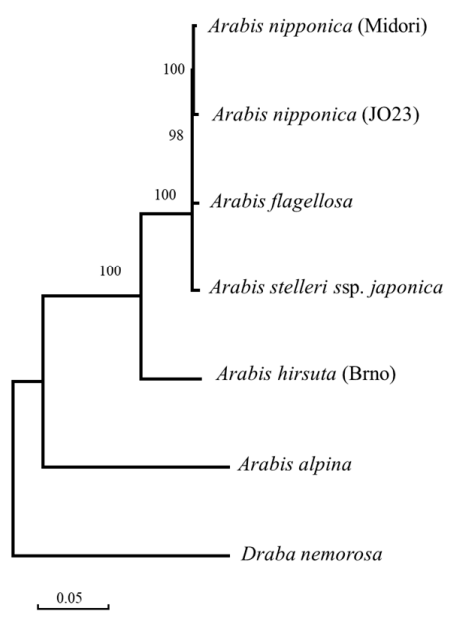

B) Synonymous site in concatenated CDSs

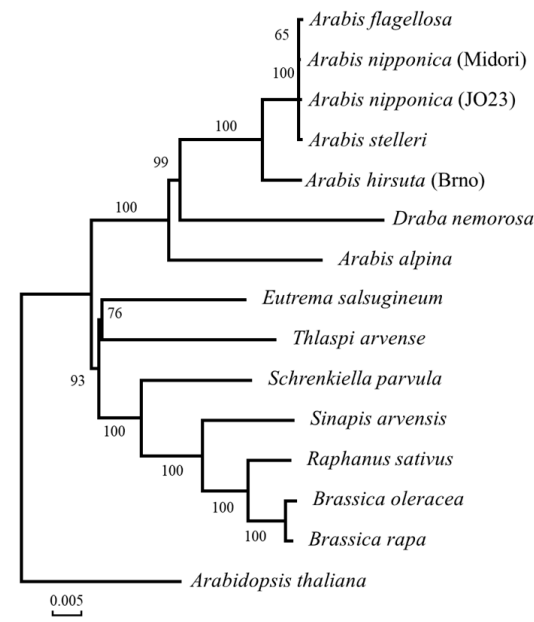

Figure 2. Chloroplast genome-based phylogenetic trees of Arabis species. The neighbor-joining trees were constructed using both (A) whole chloroplast genomes and (B) synonymous divergence from concatenated CDS. Numbers beside the nodes indicate bootstrap probabilities (\%). Scale bars are shown at the bottom left of each tree.

Table 2. Divergence between species.

\begin{tabular}{|c|c|c|c|c|}
\hline & Compared Species & & \# of Differences & $\begin{array}{l}\text { Divergence (\%: Ks with } \\
\text { JC Correction) }\end{array}$ \\
\hline Draba nemorosa & vs. & Arabis alpina & 4475 & 2.976 \\
\hline Draba nemorosa & vs. & Arabis hirsuta & 4219 & 2.801 \\
\hline Draba nemorosa & vs. & Arabis flagellosa & 4262 & 2.765 \\
\hline Draba nemorosa & vs. & Arabis stelleri & 4171 & 2.771 \\
\hline Draba nemorosa & vs. & Arabis nipponica (JO23) & 4150 & 2.757 \\
\hline Draba nemorosa & vs. & Arabis nipponica (Midori) & 4131 & 2.745 \\
\hline Arabis alpina & vs. & Arabis hirsuta & 3566 & 2.366 \\
\hline Arabis alpina & vs. & Arabis flagellosa & 3571 & 2.371 \\
\hline Arabis alpina & vs. & Arabis stelleri & 3565 & 2.366 \\
\hline Arabis alpina & vs. & Arabis nipponica (JO23) & 3564 & 2.366 \\
\hline Arabis alpina & vs. & Arabis nipponica (Midori) & 3547 & 2.355 \\
\hline Arabis hirsuta & vs. & Arabis flagellosa & 1245 & 0.815 \\
\hline Arabis hirsuta & vs. & Arabis stelleri & 1253 & 0.82 \\
\hline Arabis hirsuta & vs. & Arabis nipponica (JO23) & 1234 & 0.808 \\
\hline Arabis hirsuta & vs. & Arabis nipponica (Midori) & 1214 & 0.795 \\
\hline Arabis flagellosa & vs. & Arabis stelleri & 132 & 0.086 \\
\hline Arabis flagellosa & vs. & Arabis nipponica (JO23) & 111 & 0.072 \\
\hline Arabis flagellosa & vs. & Arabis nipponica (Midori) & 86 & 0.056 \\
\hline Arabis stelleri & vs. & Arabis nipponica (JO23) & 130 & 0.085 \\
\hline Arabis stelleri & vs. & Arabis nipponica (Midori) & 104 & 0.068 \\
\hline Arabis nipponica (JO23) & vs. & Arabis nipponica (Midori) & 55 & 0.036 \\
\hline
\end{tabular}




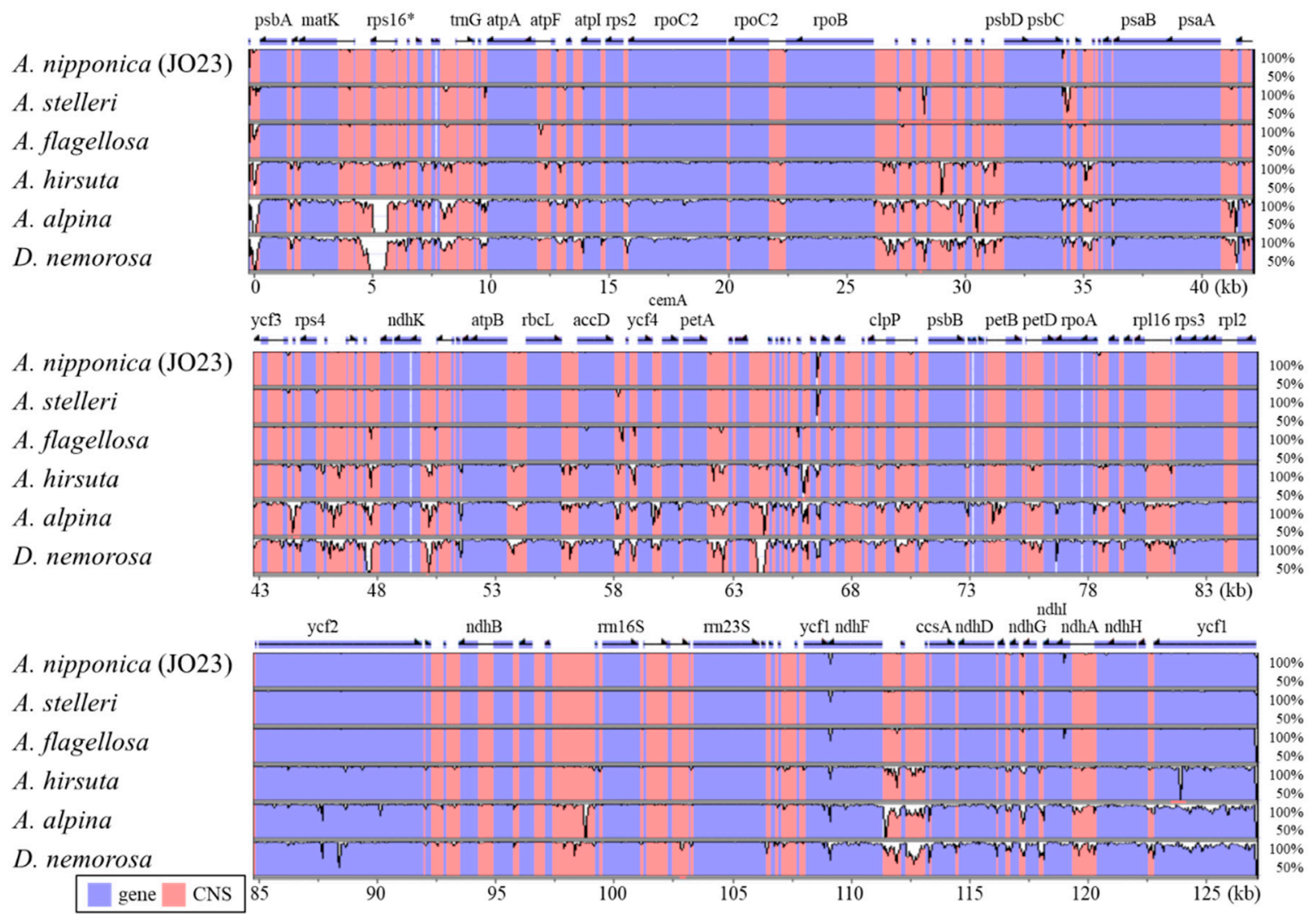

Figure 3. Alignment of the seven chloroplast genomes. VISTA-based identity plots of chloroplast genomes from six Arabis species and Draba nemorosa are compared to A. nipponica strain Midori. Arrows above the alignment indicate genes and their orientation. The names of genes $\geq 500 \mathrm{bp}$ in length are also shown. A 70\% identity cut-off was used for making the plots, and the Y-axis represents percent identity (50-100\%), while the X-axis represents the location in the chloroplast genome. The blue and pink regions indicate genes and conserved noncoding sequences, respectively.

\subsection{Distribution of Simple Sequence Repeats in the Chloroplast Genomes}

Because the extremely low divergence among the East Asian Arabis species made it difficult to resolve their evolutionary relationships, other highly variable markers were needed. Therefore, simple sequence repeat (SSR) regions throughout the chloroplast genome were assessed for their ability to provide high-resolution species definition. A total of 74 mono-nucleotide, 22 di-nucleotide, and two tri-nucleotide repeat regions of $\geq 10$ base pairs in length were identified (see Table 3 ). However, these repeat regions were still unable to completely resolve the relationships of the East Asian Arabis species. Fifty of the 98 SSRs exhibited no variation among the East Asian Arabis species, while only 29 SSRs exhibited species-specific variation, including nine in A. flagellosa, 15 in A. stelleri, four in A. nipponica strain JO23, and one in A. nipponica strain Midori. Five of the SSRs were shared by the two A. nipponica strains, which suggests that they were also species-specific. Although the two A. nipponica strains were similar to each other, $A$. flagellosa, A. stelleri, and $A$. nipponica differ to a similar degree in terms of of variable SSRs, which suggests that the occurrence of chloroplast capture would be independent or still ongoing. This was suggested by the patterns of nucleotide substitutions. 
Table 3. Simple sequence repeats (SSRs) in Arabis chloroplast genome.

\begin{tabular}{|c|c|c|c|c|c|c|c|c|c|}
\hline \multicolumn{2}{|c|}{$\begin{array}{c}\text { Position in } \\
\text { A. nipponica } \\
\text { (Midori) Genome }\end{array}$} & UNIT & & \multicolumn{2}{|c|}{ A. nipponica } & A. stelleri & A. flagellosa & A. hirsuta & A. alpina \\
\hline 287 & 318 & AT & & 16 & 15 & 15 & 12 & $\begin{array}{l}13 \text { with } 2 \\
\text { mutations }\end{array}$ & $\begin{array}{c}29 \mathrm{bp} \text { with several } \\
\text { mutations }\end{array}$ \\
\hline 1922 & 1932 & $\mathrm{~A}$ & & 11 & 11 & 9 & 12 & 11 & 9 \\
\hline 7713 & 7727 & $\mathrm{~T}$ & & 15 & 15 & 15 & 15 & 12 & 11 \\
\hline 7729 & 7738 & A & & 10 & 10 & 10 & 9 & 10 & 10 \\
\hline 8203 & 8216 & TA & & 7 & 6 & 7 & 7 & 6 & 6 \\
\hline 8273 & 8282 & TA & & 5 & 5 & 5 & 5 & 5 & 6 \\
\hline 8289 & 8302 & AT & & 7 & 7 & 6 & 7 & 8 & 6 \\
\hline 8321 & 8330 & TA & & 5 & 5 & 4 & 5 & 5 & deletion \\
\hline 13,010 & 13,018 & $\mathrm{~T}$ & & 9 & 9 & 10 & 9 & T7AT2 & T10AT2 \\
\hline 13,810 & 13,821 & ATT & & 4 & 4 & 4 & 4 & 4 & ATTATATTCTT \\
\hline 14,101 & 14,110 & A & & 10 & 10 & 14 & 10 & 12 & 10 \\
\hline 18,027 & 18,037 & $\mathrm{~T}$ & CDS & 11 & 11 & 11 & 11 & 11 & 11 \\
\hline 19,398 & 19,408 & TA & & 5 & 5 & 5 & 5 & 5 & 5 \\
\hline 22,549 & 22,558 & $\mathrm{~T}$ & & 10 & 10 & 11 & 10 & 9 & 15 \\
\hline 25,777 & 25,786 & $\mathrm{~T}$ & CDS & 10 & 10 & 10 & 10 & 10 & 10 \\
\hline 27,601 & 27,611 & G & & 11 & 11 & 11 & 15 & 12 & 9 \\
\hline 28,808 & 28,817 & $\mathrm{~T}$ & & 10 & 10 & 9 & 10 & 10 & T5CT3G2 \\
\hline 30,293 & 30,310 & A & & 18 & 17 & 17 & 18 & 12 & A4CA5 \\
\hline 30,737 & 30,751 & $\mathrm{~T}$ & & 15 & 15 & 14 & 15 & 15 & 5 \\
\hline 30,830 & 30,839 & $\mathrm{~A}$ & & 10 & 9 & 11 & 10 & 8 & 6 \\
\hline 43,887 & 43,895 & $\mathrm{~T}$ & & 9 & 15 & T4AT4AT4 & T4AT4 & 4 & 4 \\
\hline 45,038 & 45,046 & $\mathrm{~T}$ & & 9 & 9 & 9 & 10 & 8 & 7 \\
\hline 45,771 & 45,788 & $\mathrm{~T}$ & & 18 & 18 & 18 & 18 & 13 & 9 \\
\hline 46,034 & 46,057 & A & & 24 & 24 & 24 & 24 & 16 & 11 \\
\hline 46,116 & 46,133 & $\mathrm{AT}$ & & 9 & 9 & 9 & 8 & 9 & 7 \\
\hline 46,135 & 46,144 & $\mathrm{TA}$ & & 5 & 5 & 5 & 5 & 5 & 3 \\
\hline 46,782 & 46,791 & $\mathrm{~T}$ & & 10 & 11 & 10 & 11 & 14 & 10 \\
\hline 47,368 & 47,378 & A & & 11 & 11 & 12 & 12 & 10 & 13 \\
\hline 47,586 & 47,595 & $\mathrm{~T}$ & & 10 & 10 & 10 & 10 & 13 & ТСТ8 \\
\hline 47,624 & 47,633 & A & & 10 & 10 & 11 & 11 & 8 & 7 \\
\hline 49,061 & 49,070 & $\mathrm{~T}$ & & 10 & 10 & 11 & 10 & 8 & T3AT10 \\
\hline 49,631 & 49,640 & $\mathrm{~T}$ & & 10 & 10 & 10 & 10 & 8 & 8 \\
\hline 50,329 & 50,340 & A & & 12 & 12 & 12 & 12 & 11 & 11 \\
\hline 51,202 & 51,211 & $\mathrm{TA}$ & & 5 & 5 & 5 & 5 & $19 \mathrm{nt}$ & deletion \\
\hline 51,215 & 51,230 & $\mathrm{~T}$ & & 16 & 17 & 17 & 16 & 13 & 13 \\
\hline 53,088 & 53,097 & $\mathrm{~T}$ & CDS & 10 & 10 & 10 & 10 & 10 & 12 \\
\hline 53,592 & 53,601 & $\mathrm{C}$ & & 10 & 11 & 9 & 12 & 9 & 9 \\
\hline 55,477 & 55,490 & $\mathrm{~T}$ & & 14 & 14 & 14 & 14 & complement A11 & complement A13 \\
\hline 55,891 & 55,906 & $\mathrm{~T}$ & & 16 & 16 & 16 & 16 & 13 & 15 \\
\hline 56,476 & 56,485 & $\mathrm{~T}$ & & 10 & 10 & 10 & 10 & 10 & $\mathrm{~A} 2 \mathrm{~T} 8$ \\
\hline 58,301 & 58,310 & $\mathrm{~T}$ & & 10 & 10 & 10 & 10 & 10 & 6 \\
\hline 59,338 & 59,348 & $\mathrm{~T}$ & & 11 & 10 & 9 & 11 & 11 & 4 \\
\hline 61,731 & 61,739 & $\mathrm{C}$ & & 9 & 13 & 9 & 12 & 8 & C3AC3 \\
\hline 62,108 & 62,117 & TA & & 5 & 5 & 5 & 5 & 6 & 4 \\
\hline
\end{tabular}


Table 3. Cont.

\begin{tabular}{|c|c|c|c|c|c|c|c|c|}
\hline \multicolumn{2}{|c|}{$\begin{array}{c}\text { Position in } \\
\text { A. nipponica } \\
\text { (Midori) Genome }\end{array}$} & \multirow{2}{*}{$\begin{array}{c}\text { UNIT } \\
\mathrm{T}\end{array}$} & \multicolumn{2}{|c|}{ A. nipponica } & \multirow{2}{*}{$\begin{array}{c}\text { A. stelleri } \\
13\end{array}$} & \multirow{2}{*}{$\begin{array}{c}\text { A. flagellosa } \\
13\end{array}$} & \multirow{2}{*}{$\begin{array}{c}\text { A. hirsuta } \\
13\end{array}$} & \multirow{2}{*}{ A. alpino } \\
\hline 76,614 & 76,626 & & 13 & 13 & & & & \\
\hline 78,154 & 78,162 & TTG & 3 & 5 & 3 & 3 & 4 & 2 \\
\hline 80,484 & 80,493 & A & 10 & 11 & 10 & 10 & 10 & 9 \\
\hline 81,019 & 81,035 & $\mathrm{~T}$ & 17 & 17 & 17 & 17 & 17 & 17 \\
\hline 81,178 & 81,191 & $\mathrm{~T}$ & 14 & 14 & 14 & 14 & 18 & 8 \\
\hline 82,568 & 82,578 & A & 11 & 10 & 9 & 10 & 9 & 10 \\
\hline 83,489 & 83,498 & TA & 5 & 5 & 5 & 5 & 5 & 4 \\
\hline 93,127 & 93,136 & TA & 5 & 5 & 5 & 5 & 5 & 4 \\
\hline 97,975 & 97,984 & A & 10 & 10 & 10 & 10 & 12 & 9 \\
\hline 98,781 & 98,791 & $\mathrm{~T}$ & 11 & 11 & 11 & 11 & 10 & 14 \\
\hline 107,287 & 107,295 & AT & 5 & 5 & 5 & 5 & 5 & 7 \\
\hline 107,313 & 107,324 & $\mathrm{~T}$ & 12 & 11 & 13 & 13 & T2(AT)4T7 & 14 \\
\hline 111,481 & 111,490 & TA & 5 & 5 & 5 & 5 & TA2TGTA & 4 \\
\hline 111,589 & 111,598 & AT & 5 & 5 & 5 & 5 & 5 & 10 \\
\hline 111,665 & 111,672 & $\mathrm{~T}$ & 8 & 8 & 10 & 8 & 7 & 10 \\
\hline 111,801 & 111,810 & A & A7CA2 & A7CA2 & 10 & A7CA2 & A7CA2 & A7TAC \\
\hline 112,472 & 112,481 & A & 10 & 10 & 10 & 10 & 11 & 10 \\
\hline 116,836 & 116,845 & $\mathrm{~T}$ & 10 & 9 & 10 & 11 & T7AT3 & 10 \\
\hline 123,173 & 123,184 & $\mathrm{~T}$ & 12 & 12 & 12 & 12 & 12 & 12 \\
\hline 123,285 & 123,383 & $\mathrm{~T}$ & 10 & 10 & 10 & 10 & 10 & 10 \\
\hline 123,884 & 123,893 & $\mathrm{~T}$ & 10 & 10 & 10 & 10 & 10 & 10 \\
\hline 123,975 & 123,987 & A & 13 & 13 & 13 & 13 & 13 & 13 \\
\hline 124,356 & 124,365 & TA & 5 & 5 & 5 & 5 & 5 & 5 \\
\hline 124,874 & 124,886 & $\mathrm{~T}$ & 13 & 13 & 13 & 13 & 13 & 13 \\
\hline 125,029 & 125,041 & A & 13 & 13 & 13 & 13 & 13 & 13 \\
\hline 126,052 & 125,385 & $\mathrm{~T}$ & 15 & 15 & 15 & 15 & 15 & 17 \\
\hline 126,087 & 126,097 & $\mathrm{~T}$ & 11 & 11 & 11 & 11 & 11 & 11 \\
\hline 126,117 & 126,128 & A & 12 & 12 & 12 & 12 & 12 & 12 \\
\hline 126,952 & 126,962 & $\mathrm{~T}$ & 11 & 11 & 11 & 11 & Т8СТ2 & Т8СТ2 \\
\hline 127,241 & 127,252 & A & 12 & 12 & 12 & 12 & 6 & 6 \\
\hline
\end{tabular}

\subsection{Mitochondrial Genome Analysis}

Chloroplast capture could have originated from hybridization events that also affected other cytoplasmic genomes. Due to this, variation in the mitochondrial genome sequences was analyzed. Mapping next-generation sequencing (NGS) reads to the Eruca vesicaria mitochondrial genome revealed that 29 sites with five or more mapped reads varied among the A. nipponica strain Midori, A. flagellosa, and $A$. hirsuta (see Table 4). Twenty-eight of the sites were conserved among A. nipponica and A. flagellosa. One site was specific to $A$. nipponica and provided $100 \%$ support for the relationship between $A$. nipponica and A. flagellosa. Even though reliability decreased, 123 of 125 sites with two or more reads (98.4\%) also supported the similarity of the A. nipponica and A. flagellosa mitochondrial genomes. These findings suggest that the hybridization history of the species affects both the chloroplast and the mitochondrial genomes similarly.

Table 4. Nucleotide variation in the mitochondrial genome of Arabis species.

\begin{tabular}{|c|c|c|c|c|c|}
\hline & & \multicolumn{4}{|c|}{ Number of Mapped Reads } \\
\hline & & 5 and More & 4 and More & 3 and More & 2 and More \\
\hline Number of variable sites & Total & 29 & 46 & 74 & 129 \\
\hline \multirow{2}{*}{ Specific to } & A. flagellosa & 0 & 0 & 0 & 3 \\
\hline & A. hirsuta & 14 & 25 & 35 & 62 \\
\hline \multirow{2}{*}{ Shared with } & $\begin{array}{l}\text { A. nipponica and } \\
\text { A. hirsuta }\end{array}$ & 0 & 0 & 1 & 1 \\
\hline & $\begin{array}{l}\text { A. flagellosa and } \\
\text { A. hirsuta }\end{array}$ & 0 & 0 & 1 & 1 \\
\hline
\end{tabular}




\section{Discussion}

Chloroplast capture results in the incongruence of chloroplast and nuclear phylogenies, which has been reported in many plant taxa and is considered common among plants [17,18,26-37]. Furthermore, it is possible that the introgression of chloroplast genomes occurs more frequently than that of nuclear genomes as a result of uniparental inheritance, lack of recombination, and low selective constraint [38-40]. Chloroplast capture could occur by using several factors including sampling error, convergence, evolutionary rate heterogeneity, wrong lineage sorting, and hybridization/introgression [17]. Introgression-induced chloroplast capture occurred through hybridization between distant but compatible species, which was followed by backcrossing with pollen donor species [41,42].

East Asian Arabis species have previously been reported to show evidence of chloroplast capture [14,16]. More specifically, detailed phylogenetic analyses of nuclear and chloroplast marker genes has suggested that $A$. nipponica, $A$. stelleri, and $A$. takeshimana originated from the hybridization of A. hirsuta (or A. sagittata) and East Asian Arabis species (close to A. serrata, A. paniculata, and A. flagellosa), which act as paternal and maternal parents, respectively [14,16]. In the present study, comparing the whole chloroplast genomes of four plants from three East Asian Arabis species (two A. nipponica, one each of $A$. stelleri, and $A$. flagellosa) revealed genome-wide similarities that indicated chloroplast capture by $A$. nipponica and $A$. stelleri. The study also compared the species' partial mitochondrial genomes, which indicated a closer relationship between $A$. nipponica and A. flagellosa than between the former and European A. hirsuta. This suggested that A. nipponica also has a history of mitochondrial capture. This is not surprising, because hybridization and backcrossing could have similar effects on both organellar genomes. Also, cyto-nuclear incompatibility caused by a mitochondrial genome could lead cytoplasmic replacement to exhibit chloroplast capture [17,41,42]. The pattern of variation in the mitochondrial genomes suggested that both the chloroplast and mitochondrial genomes were co-transmitted during the evolutionary history of East Asian Arabis species. Future research should focus on the process of chloroplast (organellar) capture. Simple backcrossing could show the mechanisms of cytoplasm replacement and could produce results in as few as a hundred generations under certain conditions [42]. In the present study, the divergence between the genomes of hybrid-origin species and putative pollen-donor species was similar to the divergence observed within species, which suggests that the hybridization event was relatively recent. Nuclear genome markers are needed to estimate the proportion of parental genome fragments in the current nuclear genome of A. nipponica.

\section{Materials and Methods}

\subsection{Plant Materials}

Arabis nipponica (A. hirsuta var. nipponica, sampled from Midori, Gifu Prefecture, Japan), A. flagellosa (sampled from Kifune, Kyoto Prefecture, Japan), and A. hirsuta (strain Brno from Ulm Botanical Garden, Germany) were used in the present study.

\subsection{DNA Isolation, NGS Sequencing, and Genome Assembly}

Chloroplasts were isolated from A. hirsuta and A. nipponica as described in Okegawa and Motohashi [43]. DNA was isolated from the chloroplasts using the DNeasy Plant Mini Kit (Qiagen, Valencia, CA, USA), while the total DNA was isolated from leaves of A. flagellosa. NGS libraries were constructed using the Nextera DNA Sample Preparation Kit (Illumina, San Diego, CA, USA) and sequenced as single-ended reads using the NextSeq500 platform (Illumina). About 2 Gb (1.4 Gb, 12 M clean reads) of sequences were obtained for $A$. flagellosa (43 $\mathrm{Mb}$ mapped reads, $282.69 \times$ coverage). Additionally, $400 \mathrm{Mb}(300 \mathrm{Mb}, 2.5 \mathrm{M}$ clean reads) were obtained for both A. hirsuta (64 Mb mapped reads, $417.17 \times$ coverage) and $A$. nipponica $(72 \mathrm{Mb}$ mapped reads, $455.87 \times$ coverage). The generated reads were assembled using velvet 1.2.10 [44] and assembled into complete chloroplast genomes by mapping to previously published whole chloroplast genome sequences. Sequence gaps were 
resolved using Sanger sequencing. Genes were annotated using DOGMA [45] and BLAST. The newly constructed chloroplast genomes were deposited in the DDBJ database under the accession numbers LC361349-51. Finally, the circular chloroplast genome maps were drawn using OGDRAW [46].

\subsection{Molecular Evolutionary Analyses}

The whole chloroplast genome sequences of A. nipponica (strain JO23: AP009369), A. stelleri (KY126841) [23], A. alpina (HF934132) [25], and D. nemorosa (strain JO21: AP009373) in the GenBank were also used. Whole chloroplast sequences were aligned in order to construct neighbor-joining trees with Jukes and Cantor distances. The sequences of 77 known functional genes were linked in a series after excluding initiation and stop codons and were then used for phylogenetic analyses along with sequences from the related clade species Brassica oleracea (KR233156) [47], B. rapa (DQ231548), Eutrema salsugineum (KR584659) [48], Raphanus sativus (KJ716483) [49], Scherenkiella parvula (KT222186) [48], Sinapis arvensis (KU050690), and Thlaspi arvense (KX886351) [21] using A. thaliana (AP000423) [50] as an outgroup. The synonymous divergence of the concatenated CDS was estimated using the Nei and Gojobori method. All phylogenetic analyses were performed using MEGA 7.0 [51]. Levels of divergence throughout the chloroplast genome were visualized using mVISTA [52] with Shuffle-LAGAN alignment [53].

\subsection{Mapping NGS Reads to Mitochondrial Genome Sequences}

Because the chloroplast isolation method used in the present study did not completely exclude mitochondria, about $1 \%$ of the sequence reads were derived from mitochondrial genomes. Although this proportion is too low to be useful for assembling whole mitochondrial genomes, the reads were nevertheless mapped to the mitochondrial genome of Eruca vesicaria (KF442616) [54] in order to measure mitochondrial genome divergence. Regions with at least five mapped reads were used for the analysis.

Acknowledgments: This study was supported in part by JSPS KAKENHI Grant Number 17K19361 and Grants-in-Aid from MEXT-Supported Program for the Strategic Research Foundation at Private Universities (S1511023) to Akira Kawabe.

Author Contributions: Akira Kawabe designed the study. Hiroaki Nukii and Hazuka Y. Furihata performed the experiments. Akira Kawabe and Hazuka Y. Furihata analyzed the data. Akira Kawabe wrote the manuscript. All authors read and approved the final manuscript.

Conflicts of Interest: The authors declare no conflict of interest.

\section{References}

1. Al-Shehbaz, I.A. Transfer of most North American species of Arabis to Boechera (Brassicaceae). Novon 2003, 13, 381-391. [CrossRef]

2. O'Kane, S.L.; Al-Shehbaz, I.A. Phylogenetic Position and Generic Limits of Arabidopsis (Brassicaceae) Based on Sequences of Nuclear Ribosomal DNA. Ann. Mo. Bot. Gard. 2003, 90, 603-612. [CrossRef]

3. Al-Shehbaz, I.A.; Beilstein, M.A.; Kellogg, E.A. Systematics and phylogeny of the Brassicaceae (Cruciferae): An overview. Plant Syst. Evol. 2006, 259, 89-120. [CrossRef]

4. Al-Shehbaz, I.A.; German, D.A.; Karl, R.; Ingrid, J.T.; Koch, M.A. Nomenclatural adjustments in the tribe Arabideae (Brassicaceae). Plant Div. Evol. 2011, 129, 71-76. [CrossRef]

5. Koch, M.A.; Karl, R.; German, D.A.; Al-Shehbaz, I.A. Systematics, taxonomy and biogeography of three new Asian genera of Brassicaceae tribe Arabideae: An ancient distribution circle around the Asian high mountains. Taxon 2012, 61, 955-969.

6. Kiefer, M.; Schmickl, R.; German, D.A.; Mandáková, T.; Lysak, M.A.; Al-Shehbaz, I.A.; Franzke, A.; Mummenhoff, K.; Stamatakis, A.; Koch, M.A. BrassiBase: Introduction to a novel knowledge database on Brassicaceae evolution. Plant Cell Physiol. 2014, 55, e3. [CrossRef] [PubMed] 
7. Ansell, S.W.; Grundmann, M.; Russell, S.J.; Schneider, H.; Vogel, J.C. Genetic discontinuity, breeding-system change and population history of Arabis alpina in the Italian Peninsula and adjacent Alps. Mol Ecol. 2008, 17, 2245-2257. [CrossRef] [PubMed]

8. Bergonzi, S.; Albani, M.C.; ver Loren van Themaat, E.; Nordström, K.J.; Wang, R.; Schneeberger, K.; Moerland, P.D.; Coupland, G. Mechanisms of age-dependent response to winter temperature in perennial flowering of Arabis alpina. Science 2013, 340, 1094-1097. [CrossRef] [PubMed]

9. Karl, R.; Koch, M.A. A world-wide perspective on crucifer speciation and evolution: Phylogenetics, biogeography and trait evolution in tribe Arabideae. Ann. Bot. 2013, 112, 983-1001. [CrossRef] [PubMed]

10. Toräng, P.; Vikström, L.; Wunder, J.; Wötzel, S.; Coupland, G.; Ågren, J. Evolution of the selfing syndrome: Anther orientation and herkogamy together determine reproductive assurance in a self-compatible plant. Evolution 2017, 71, 2206-2218. [CrossRef] [PubMed]

11. Heidel, A.J.; Kiefer, C.; Coupland, G.; Rose, L.E. Pinpointing genes underlying annual/perennial transitions with comparative genomics. BMC Genom. 2016, 17, 921. [CrossRef] [PubMed]

12. Willing, E.M.; Rawat, V.; Mandáková, T.; Maumus, F.; James, G.V.; Nordström, K.J.; Becker, C.; Warthmann, N.; Chica, C.; Szarzynska, B.; et al. Genome expansion of Arabis alpina linked with retrotransposition and reduced symmetric DNA methylation. Nat. Plants 2015, 1, 14023. [CrossRef] [PubMed]

13. Jiao, W.B.; Accinelli, G.G.; Hartwig, B.; Kiefer, C.; Baker, D.; Severing, E.; Willing, E.M.; Piednoel, M.; Woetzel, S.; Madrid-Herrero, E.; et al. Improving and correcting the contiguity of long-read genome assemblies of three plant species using optical mapping and chromosome conformation capture data. Genome Res. 2017, 27, 778-786. [CrossRef] [PubMed]

14. Koch, M.A.; Karl, R.; Kiefer, C.; Al-Shehbaz, I.A. Colonizing the American continent: Systematics of the genus Arabis in North America (Brassicaceae). Am. J. Bot. 2010, 97, 1040-1057. [CrossRef] [PubMed]

15. Karl, R.; Kiefer, C.; Ansell, S.W.; Koch, M.A. Systematics and evolution of Arctic-Alpine Arabis alpina (Brassicaceae) and its closest relatives in the eastern Mediterranean. Am. J. Bot. 2012, 99, 778-794. [CrossRef] [PubMed]

16. Karl, R.; Koch, M.A. Phylogenetic signatures of adaptation: The Arabis hirsuta species aggregate (Brassicaceae) revisited. Perspect. Plant Ecol. Evol. Syst. 2014, 16, 247-264. [CrossRef]

17. Rieseberg, L.H.; Soltis, D.E. Phylogenetic consequences of cytoplasmic gene flow in plants. Evolut. Trends Plants 1991, 5, 65-84.

18. Soltis, D.E.; Kuzoff, R.K. Discordance between nuclear and chloroplast phylogenies in the Heuchera group (Saxifragaceae). Evolution 1995, 49, 727-742. [CrossRef] [PubMed]

19. Ruhfel, B.R.; Gitzendanner, M.A.; Soltis, P.S.; Soltis, D.E.; Burleigh, J.G. From algae to angiosperms-inferring the phylogeny of green plants (Viridiplantae) from 360 plastid genomes. BMC Evol. Biol. 2014, 14, 23. [CrossRef] [PubMed]

20. Hohmann, N.; Wolf, E.M.; Lysak, M.A.; Koch, M.A. A Time-calibrated road map of brassicaceae species radiation and evolutionary history. Plant Cell 2015, 27, 2770-2784. [CrossRef] [PubMed]

21. Guo, X.; Liu, J.; Hao, G.; Zhang, L.; Mao, K.; Wang, X.; Zhang, D.; Ma, T.; Hu, Q.; Al-Shehbaz, I.A.; Koch, M.A. Plastome phylogeny and early diversification of Brassicaceae. BMC Genom. 2017, 18, 176. [CrossRef] [PubMed]

22. Mandáková, T.; Hloušková, P.; German, D.A.; Lysak, M.A. Monophyletic origin and evolution of the largest crucifer genomes. Plant Physiol. 2017, 174, 2062-2071. [CrossRef] [PubMed]

23. Raman, G.; Park, V.; Kwak, M.; Lee, B.; Park, S. Characterization of the complete chloroplast genome of Arabis stellari and comparisons with related species. PLoS ONE 2017, 12, e0183197. [CrossRef] [PubMed]

24. Jordon-Thaden, I.; Hase, I.; Al-Shehbaz, I.A.; Koch, M.A. Molecular phylogeny and systematics of the genus Draba (Brassicaceae) and identification of its most closely related genera. Mol. Phylogenet. Evol. 2010, 55, 524-540. [CrossRef] [PubMed]

25. Melodelima, C.; Lobréaux, S. Complete Arabis alpina chloroplast genome sequence and insight into its polymorphism. Meta Gene 2013, 1, 65-75. [CrossRef] [PubMed]

26. Acosta, M.C.; Premoli, A.C. Evidence of chloroplast capture in South American Nothofagus (subgenus Nothofagus, Nothofagaceae). Mol. Phylogenet. Evol. 2010, 54, 235-242. [CrossRef] [PubMed]

27. Dorado, O.; Rieseberg, L.H.; Arias, D.M. Chloroplast DNA introgression in southern California sunflowers. Evolution 1992, 46, 566-572. [CrossRef] [PubMed] 
28. Fehrer, J.; Gemeinholzer, B.; Chrtek, J.; Bräutigam, S. Incongruent plastid and nuclear DNA phylogenies reveal ancient intergeneric hybridization in Pilosella hawkweeds (Hieracium, Cichorieae, Asteraceae). Mol. Phylogenet. Evol. 2007, 42, 347-361. [CrossRef] [PubMed]

29. Gurushidze, M.; Fritsch, R.M.; Blattner, F.R. Species-level phylogeny of Allium subgenus Melanocrommyum: Incomplete lineage sorting, hybridization and trnF gene duplication. Taxon 2010, 59, 829-840.

30. Liston, A.; Kadereit, J.W. Chloroplast DNA evidence for introgression and long distance dispersal in the desert annual Senecio flavus (Asteraceae). Plant Syst. Evol. 1995, 197, 33-41. [CrossRef]

31. Mir, C.; Jarne, P.; Sarda, V.; Bonin, A.; Lumaret, R. Contrasting nuclear and cytoplasmic exchanges between phylogenetically distant oak species (Quercus suber L. and Q. ilex L.) in Southern France: Inferring crosses and dynamics. Plant Biol. 2009, 11, 213-226. [CrossRef] [PubMed]

32. Okuyama, Y.; Fujii, N.; Wakabayashi, M.; Kawakita, A.; Ito, M.; Watanabe, M.; Murakami, N.; Kato, M. Nonuniform concerted evolution and chloroplast capture: Heterogeneity of observed introgression patterns in three molecular data partition phylogenies of Asian Mitella (Saxifragaceae). Mol. Biol. Evol. 2005, 22, 285-296. [CrossRef] [PubMed]

33. Rieseberg, L.H.; Choi, H.C.; Ham, F. Differential cytoplasmic versus nuclear introgression in Helianthus. J. Hered. 1991, 82, 489-493. [CrossRef]

34. Schilling, E.E.; Panero, J.K. Phylogenetic reticulation in subtribe Helianthinae. Am. J. Bot. 1996, 83, 939-948. [CrossRef]

35. Wolfe, A.D.; Elisens, W.J. Evidence of chloroplast capture and pollen-mediated gene flow in Penstemon sect. Peltanthera (Scrophulariaceae). Syst. Bot. 1995, 20, 395-412. [CrossRef]

36. Yi, T.S.; Jin, G.H.; Wen, J. Chloroplast capture and intra-and inter-continental biogeographic diversification in the Asian-New World disjunct plant genus Osmorhiza (Apiaceae). Mol. Phylogenet. Evol. 2015, 85, 10-21. [CrossRef] [PubMed]

37. Yuan, Y.W.; Olmstead, R.G. A species-level phylogenetic study of the Verbena complex (Verbenaceae) indicates two independent intergeneric chloroplast transfers. Mol. Phylogenet. Evol. 2008, 48, $23-33$. [CrossRef] [PubMed]

38. Avise, J.C. Molecular Markers, Natural History and Evolution, 2nd ed.; Sinauer: Sunderland, MA, USA, 2004.

39. Rieseberg, L.H.; Wendel, J. Introgression and its consequences in plants. In Hybrid Zones and the Evolutionary Process; Harrison, R., Ed.; Oxford University Press: New York, NY, USA, 1993; pp. 70-109.

40. Martinsen, G.D.; Whitham, T.G.; Turek, R.J.; Keim, P. Hybrid populations selectively filter gene introgression between species. Evolution 2001, 55, 1325-1335. [CrossRef] [PubMed]

41. Rieseberg, L.H. The role of hybridization in evolution: Old wine in new skins. Am. J. Bot. 1995, 82, 944-953. [CrossRef]

42. Tsitrone, A.; Kirkpatrick, M.; Levin, D.A. A model for chloroplast capture. Evolution 2003, 57, $1776-1782$. [CrossRef] [PubMed]

43. Okegawa, Y.; Motohashi, K. Chloroplastic thioredoxin $\mathrm{m}$ functions as a major regulator of Calvin cycle enzymes during photosynthesis in vivo. Plant J. 2015, 84, 900-913. [CrossRef] [PubMed]

44. Zerbino, D.R.; Birney, E. Velvet: Algorithms for de novo short read assembly using de Bruijn graphs. Genome Res. 2008, 18, 821-829. [CrossRef] [PubMed]

45. Wyman, S.K.; Jansen, R.K.; Boore, J.L. Automatic annotation of organellar genomes with DOGMA. Bioinformatics 2004, 20, 3252-3255. [CrossRef] [PubMed]

46. Lohse, M.; Drechsel, O.; Bock, R. OrganellarGenomeDRAW (OGDRAW) -A tool for the easy generation of high-quality custom graphical maps of plastid and mitochondrial genomes. Curr. Genet. 2007, 52, 267-274. [CrossRef] [PubMed]

47. Seol, Y.J.; Kim, K.; Kang, S.H.; Perumal, S.; Lee, J.; Kim, C.K. The complete chloroplast genome of two Brassica species, Brassica nigra and B. oleracea. Mitochondrial DNA Part A 2017, 28, 167-168. [CrossRef] [PubMed]

48. He, Q.; Hao, G.; Wang, X.; Bi, H.; Li, Y.; Guo, X.; Ma, T. The complete chloroplast genome of Schrenkiella parvula (Brassicaceae). Mitochondrial DNA Part A 2016, 27, 3527-3528. [CrossRef] [PubMed]

49. Jeong, Y.M.; Chung, W.H.; Mun, J.H.; Kim, N.; Yu, H.J. De novo assembly and characterization of the complete chloroplast genome of radish (Raphanus sativus L.). Gene 2014, 551, 39-48. [CrossRef] [PubMed]

50. Sato, S.; Nakamura, Y.; Kaneko, T.; Asamizu, E.; Tabata, S. Complete structure of the chloroplast genome of Arabidopsis thaliana. DNA Res. 1999, 6, 283-290. [CrossRef] [PubMed] 
51. Kumar, S.; Stecher, G.; Tamura, K. MEGA7: Molecular Evolutionary Genetics Analysis Version 7.0 for Bigger Datasets. Mol. Biol. Evol. 2016, 33, 1870-1874. [CrossRef] [PubMed]

52. Frazer, K.A.; Pachter, L.; Poliakov, A.; Rubin, E.M.; Dubchak, I. VISTA: Computational tools for comparative genomics. Nucleic Acids Res. 2004, 32, W273-W279. [CrossRef] [PubMed]

53. Brudno, M.; Malde, S.; Poliakov, A.; Do, C.B.; Couronne, O.; Dubchak, I.; Batzoglou, S. Glocal Alignment: Finding rearrangements during alignment. Bioinformatics 2003, 19, i54-i62. [CrossRef] [PubMed]

54. Wang, Y.; Chu, P.; Yang, Q.; Chang, S.; Chen, J.; Hu, M.; Guan, R. Complete mitochondrial genome of Eruca sativa Mill. (Garden rocket). PLoS ONE 2014, 9, e105748. [CrossRef] [PubMed]

C 2018 by the authors. Licensee MDPI, Basel, Switzerland. This article is an open access article distributed under the terms and conditions of the Creative Commons Attribution (CC BY) license (http://creativecommons.org/licenses/by/4.0/). 